Original Article

\title{
A Novel Vascular-Friendly Thoracic Stent Graft for Endovascular Repair of Acute Complicated Type B Aortic Dissection
}

Jie Jin, MD, Qingjun Jiang, MD, Jun Bai, MD, and Lefeng Qu, MD, PhD

\begin{abstract}
Purpose: To evaluate the safety and efficacy of a novel vascular-friendly thoracic stent graft for patients with acute complicated type B aortic dissection (ac-TBAD).

Methods: A multicenter retrospective study was undertaken in which we prospectively collected data in consecutive ac-TBAD patients treated by thoracic endovascular aortic repair (TEVAR) with the Ankura Thoracic Stent. Complications, true lumen rate (TLR), and mortality were recorded. Follow-up computed tomography angiography (CTA) was performed at 1, 6, and 12 months postoperatively and yearly thereafter.

Results: Altogether, 63 patients with ac-TBAD in four medical centers were included. No deaths or serious complications occurred during the perioperative period. The mean follow-up time was $30.1 \pm 18.9$ months. All-cause mortality rate was $3.1 \%(n=2)$. TEVAR-related mortality rate was $1.6 \%(n=1)$ because of retrograde type A dissection (RTAD) at 6 months. The other death was caused by acute myocardial infarction (AMI) during the third postoperative month. A distal endoleak detected at 3 months in one patient $(1.6 \%)$ was treated by reintervention. The use of this novel vascular-friendly thoracic stent graft in ac-TBAD postoperative patients significantly improved their TLR. Conclusion: The novel vascular-friendly thoracic stent graft showed satisfactory results, with favorable stability of the aortic diameter during follow-up.
\end{abstract}

Keywords: aortic dissection, vascular-friendly stent graft, complication, true lumen rate, TEVAR

\section{Introduction}

Acute complicated type B aortic dissection (ac-TBAD) is a potentially life-threatening condition associated with

Department of Vascular and Endovascular Surgery, Changzheng Hospital, Naval Medical University, Shanghai, China

Received: December 15, 2020; Accepted: March 2, 2021

Corresponding author: Lefeng Qu, MD, PhD. Department of Vascular and Endovascular Surgery, Changzheng Hospital, Naval Medical University, Shanghai 200003, China

Email: qulefeng@smmu.edu.cn

Jie Jin and Qingjun Jiang contributed equally to this work.

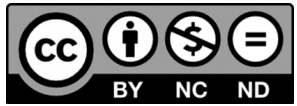

This work is licensed under a Creative Commons Attribution-NonCommercialNoDerivatives International License.

(C)2021 The Editorial Committee of Annals of Thoracic and Cardiovascular Surgery high mortality and morbidity rates. ${ }^{1,2)}$ In recent years, multiple consensus statements have recommended thoracic endovascular aortic repair (TEVAR) as the treatment of choice for ac-TBAD. ${ }^{3,4)}$ Evidence-based medicine has shown that TEVAR can significantly reduce early mortality and improve the prognosis. ${ }^{5-7)}$ Endovascular treatment for acTBAD, however, is still associated with major complications such as retrograde type A dissection (RTAD), ${ }^{8,9)}$ stent-graft migration, ${ }^{10)}$ distal true lumen collapse, ${ }^{11)}$ endoleaks, ${ }^{12)}$ and stent-graft-induced new entry. ${ }^{13)}$

Most current aortic stent grafts are designed for patients with chronic degenerative diseases such as an aortic aneurysm. Studies have revealed that complications are closely related to stent characteristics, such as the size of the graft, design of a proximal barbed shape, and the radial strength of stent. ${ }^{14)}$ Here, we introduce a novel vascular-friendly thoracic stent graft, the Ankura Thoracic Stent Graft 
(Lifetech Scientific, Shenzhen, China), which is used to treat ac-TBAD. The aim of this study was to evaluate the midterm outcomes after TEVAR with the Ankura Thoracic Stent Graft for treating ac-TBAD.

\section{Materials and Methods}

\section{Patient cohort}

This multicenter, observational descriptive study was a retrospective analysis of prospectively collected data for consecutive ac-TBAD patients treated by TEVAR with an Ankura Thoracic Stent Graft. The study protocol was approved by our institutional Ethics Committee, and all patients provided informed consent. A total of 155 consecutive patients with TBAD diagnosed by computed tomography angiography (CTA) were admitted to four medical centers from September 2013 to May 2020.

Inclusion criteria were the presence of ac-TBAD $<14$ days from the time of onset with acute symptoms. ${ }^{15)}$ Exclusion criteria were the presence of (1) unsustainable vital signs; (2) severe systemic infection; (3) chronic TBAD; (4) abdominal aorta involvement; (5) occlusion or a stenosis that is impossible to pass; (6) aortic diameter $<18 \mathrm{~mm}$ or $>42 \mathrm{~mm}$; and (7) incomplete clinical and/ or procedural data.

\section{Definitions}

Acute type B aortic dissection was defined as occurring within 14 days of pain onset to the time of the intervention. Acute complicated type $B$ dissection generally refers to the presence of a rupture or impending rupture, malperfusion, and/or refractory pain or hypertension. ${ }^{16)}$

Technical success was defined as successful deployment of the stent-graft device in the absence of a type I or type III endoleak, open surgical conversion, or death. An endoleak was defined as persistent blood flow outside the stent graft. RTAD was defined as ascending aortic dissection caused by a stent. True lumen rate (TLR) was defined as the ratio of the true lumen area to the actual lumen area. TLR was measured by Intellispace portal V9 (Philips Healthcare, Best, The Netherlands). TLR was assessed by two radiologists. Stent-graft-induced new entry was defined as a new aortic tear at the distal end of the stent graft. ${ }^{13)}$

\section{Ankura thoracic stent-graft characteristics and instructions for use}

The Ankura Thoracic stent graft system (Lifetech Scientific) is specifically designed for endovascular treatment of thoracic aortic dissection. The stent graft is preloaded in a kink-resistant delivery system with hydrophilic coating designed specifically for endovascular repair of patients with a thoracic aortic aneurysm. Among its novel characteristics, compared with other commercially available stent grafts, are (1) the metal stent is enveloped with dual-layer expanded polytetrafluoroethylene membrane; (2) no suture is required on the main body; (3) tapered design adapts to the aortic anatomy; (4) proximal miniwave bare stent and barb-free; and (5) the need for neck length of $\geq 1.5 \mathrm{~cm}$ (Fig. 1).

The size of the Ankura stent graft should fit the patient's aortic anatomy. Lifetech recommends using an oversized Ankura stent graft- that is, one that is 10-20\% larger than the inner diameter of the vessel's landing zone. The endograft comes with a delivery system that has an outer diameter of $18 \mathrm{~F}-24 \mathrm{~F}$.

\section{Operation procedure}

Generally, the heart rate should be maintained below 70 beats/min and the systolic blood pressure at $<120 \mathrm{mmHg}$. Spinal cord drainage is not required on a routine basis but is performed selectively in symptomatic patients. ${ }^{17)}$ It has been suggested that spinal pressure be maintained at $<10 \mathrm{mmHg}$, and close neurologic monitoring should be conducted for $48 \mathrm{~h}$ after the procedure.

In our study, the operation was performed in a hybrid operating room under general or locational anesthesia (whole heparinization: $0.5-1.0 \mathrm{mg} / \mathrm{kg}$ ).

(1) Access building: Arterial access was obtained by either needle puncture (Seldinger technique) or surgical arteriotomy in the common femoral artery.

(2) Angiographic evaluation: A 5F pigtail catheter was inserted into the ascending aorta with a nontraumatic guide wire to navigate the true lumen. Transesophageal echocardiography was used to confirm the exact location of the primary tear.

(3) Stent-graft implantation: The delivery system $(21 \mathrm{~F}-$ 24F) was tracked over the wire to the predetermined position to seal the entry tear. The Ankura Stent Graft (oversized by $10-20 \%$ ) was inserted via the femoral artery to completely cover the lesion. ${ }^{18)}$ Endograft's instructions for use do not impose routine use of endograft ballooning. Among those cases with planned intentional coverage of the left subclavian artery (LSA), adjunctive prophylactic revascularization was performed in selected cases.

(4) Final angiography: Angiography was performed to assess the stent's position and search for potential endoleaks. Postoperatively, the patient was routinely 

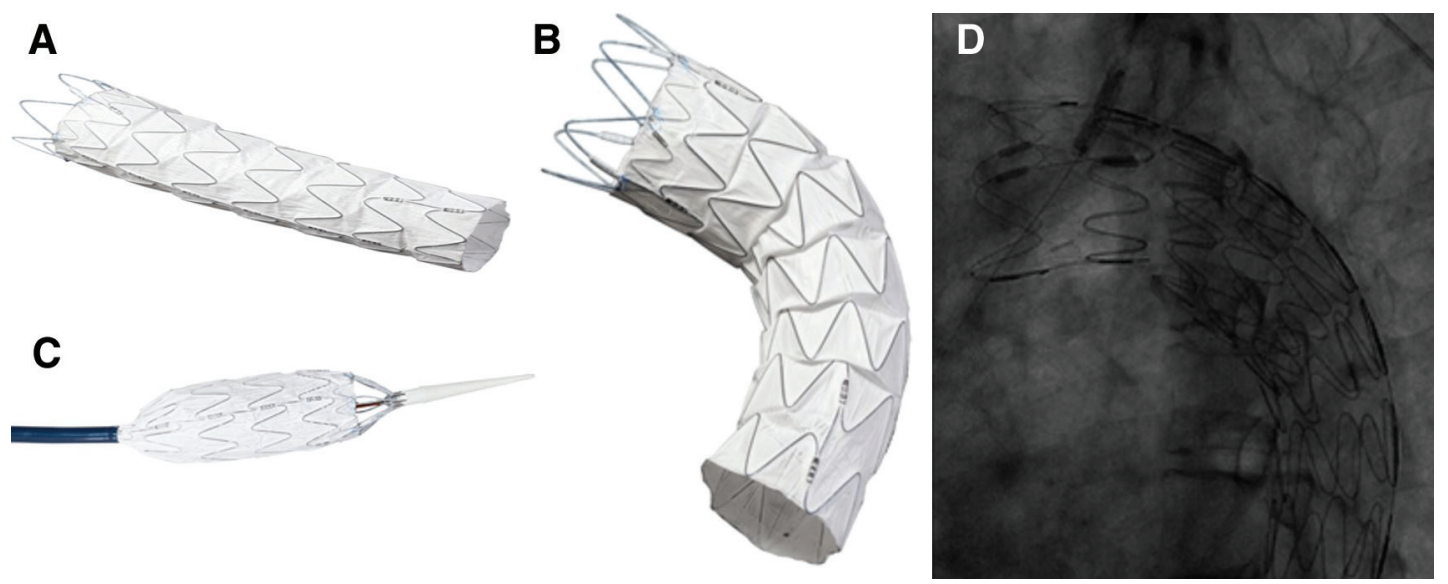

Fig. 1 (A) Proximal parallel bare stent and barb-free design, (B) tapered design, flexibility, adapt to aortic anatomy, (C) tip capture release, and (D) fluoroscopic images

transferred to the intensive care unit, later transferred to a ward, and finally discharged in good clinical condition.

\section{Outcomes measures and follow-up protocol}

Data were collected from a prospectively maintained database that included baseline characteristics, operative details, technical success, complications, and deaths. Follow-up was performed on all patients after discharge until the end of the study period (May 2020) or death. Each patient underwent CTA at 1,3, and 6 months after TEVAR and annually thereafter. The mean TLR values at the LSA level (level S), middle-thoracic aorta level (level M), and celiac trunk level (level T) were recorded. Attention was focused on the sealing zones, TLR, and aortic measurements (Fig. 2).

\section{Statistical analysis}

Statistical analysis was performed using SPSS 22.0 for Windows software (IBM Corp, Armonk, NY, USA). Categorical variables were reported as counts and proportions and continuous variables as means \pm standard deviations. Continuous and normally distributed variables were analyzed with Student's t-test and categorical variables with Pearson's $\chi^{2}$ test. The survival curve was performed using GraphPad version 8.0 software (GraphPad Software Inc., San Diego, CA, USA). A value of $\mathrm{p}<0.05$ was considered to indicate statistical significance.

\section{Results}

\section{Baseline characteristics}

There were 155 patients with TBAD admitted to the four medical centers between September 2013 and May
2020. We subsequently excluded 30 of the patients because of incomplete clinical and procedural data and 62 because of chronic TBAD. In total, 63 patients with ac-TBAD were included in this study, of whom 52 were males. The mean age of these patients was $54.2 \pm 12.3$ years. Acute complicated type B dissection included impending rupture $(3.2 \%)$, acute renal failure $(19 \%)$, visceral ischemia $(23.8 \%)$, refractory pain $(42.9 \%)$, and refractory hypertension (11.1\%). Baseline patient characteristics are shown in Table 1.

\section{Intraoperative details}

The technical success rate was $100 \%$ of all patients. Local anesthesia was used in 30 patients $(47.6 \%)$. The average duration of the procedure was $57.3 \pm 24.2 \mathrm{~min}$, and intraoperative blood loss was estimated at $55.4 \pm$ $42.6 \mathrm{~mL}$. In all, 16 patients $(25.4 \%)$ required transfusion during the perioperative period due to blood loss in a false lumen or a low preoperative hemoglobin level. Two stent grafts were implanted in 10 patients $(15.9 \%)$ according to the lesion scale. LSA reconstruction was performed in 20 patients $(31.7 \%)$ (Table 1).

\section{Thirty-day outcomes}

No deaths or serious complications (e.g., RTAD, spinal cord ischemia, type I/III endoleaks) occurred during the perioperative period. A minor type II endoleak was found in two patients. They were not treated and the endoleaks disappeared during follow-up. Spinal cord drainage was performed on two patients who presented with lower-limb muscle weakness. After prophylactic spinal cord drainage, the two patients' muscle strength of the lower limbs returned to normal without 

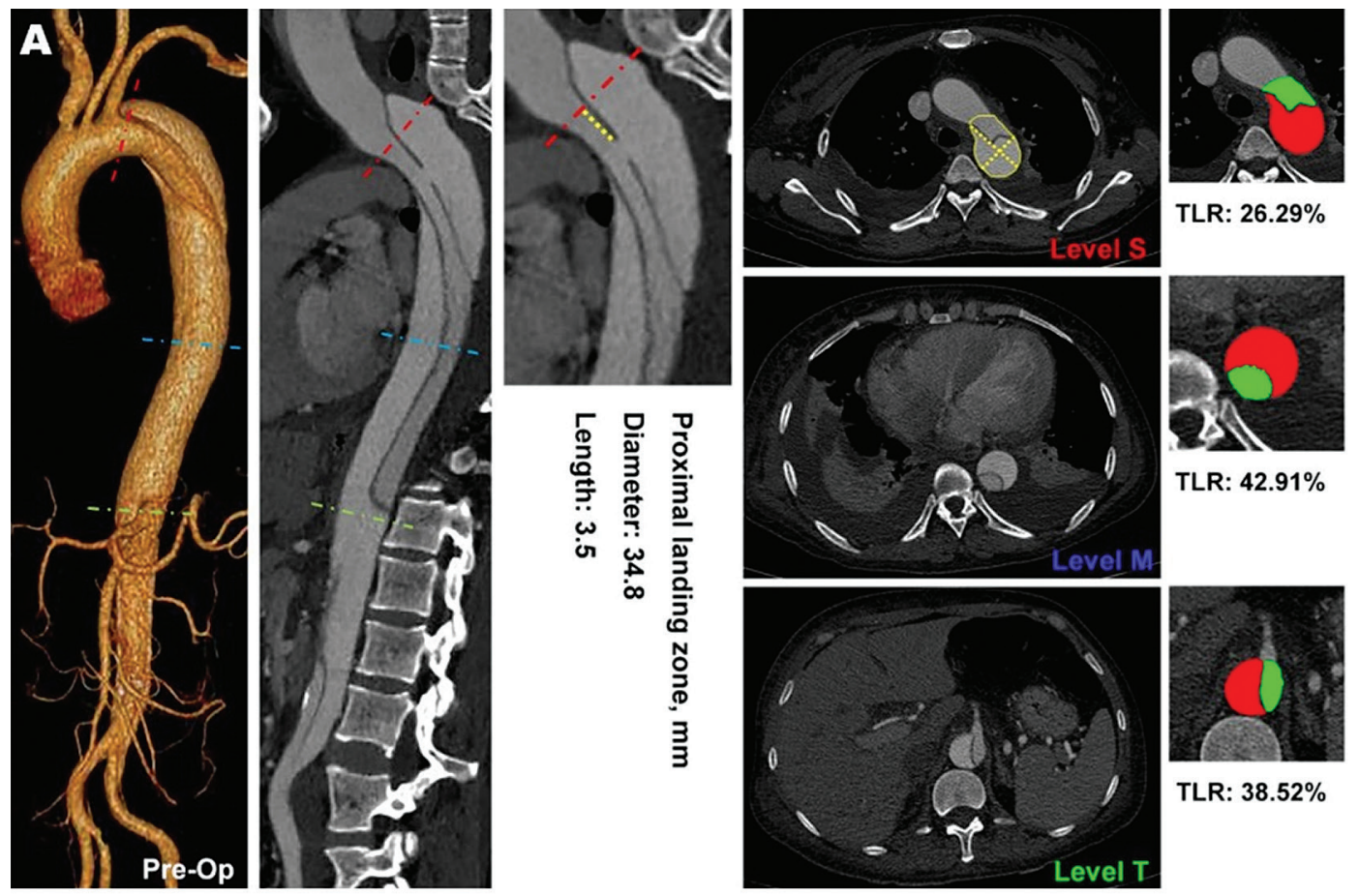

TLR: $26.29 \%$
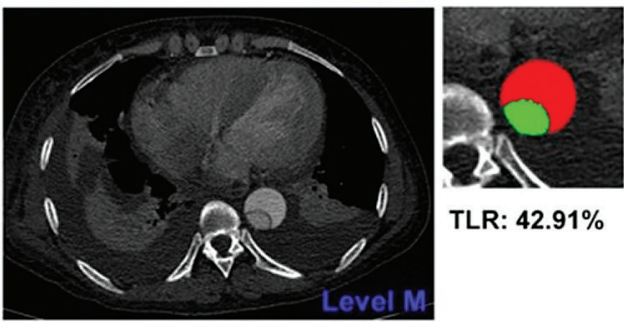

TLR: $\mathbf{4 2 . 9 1 \%}$
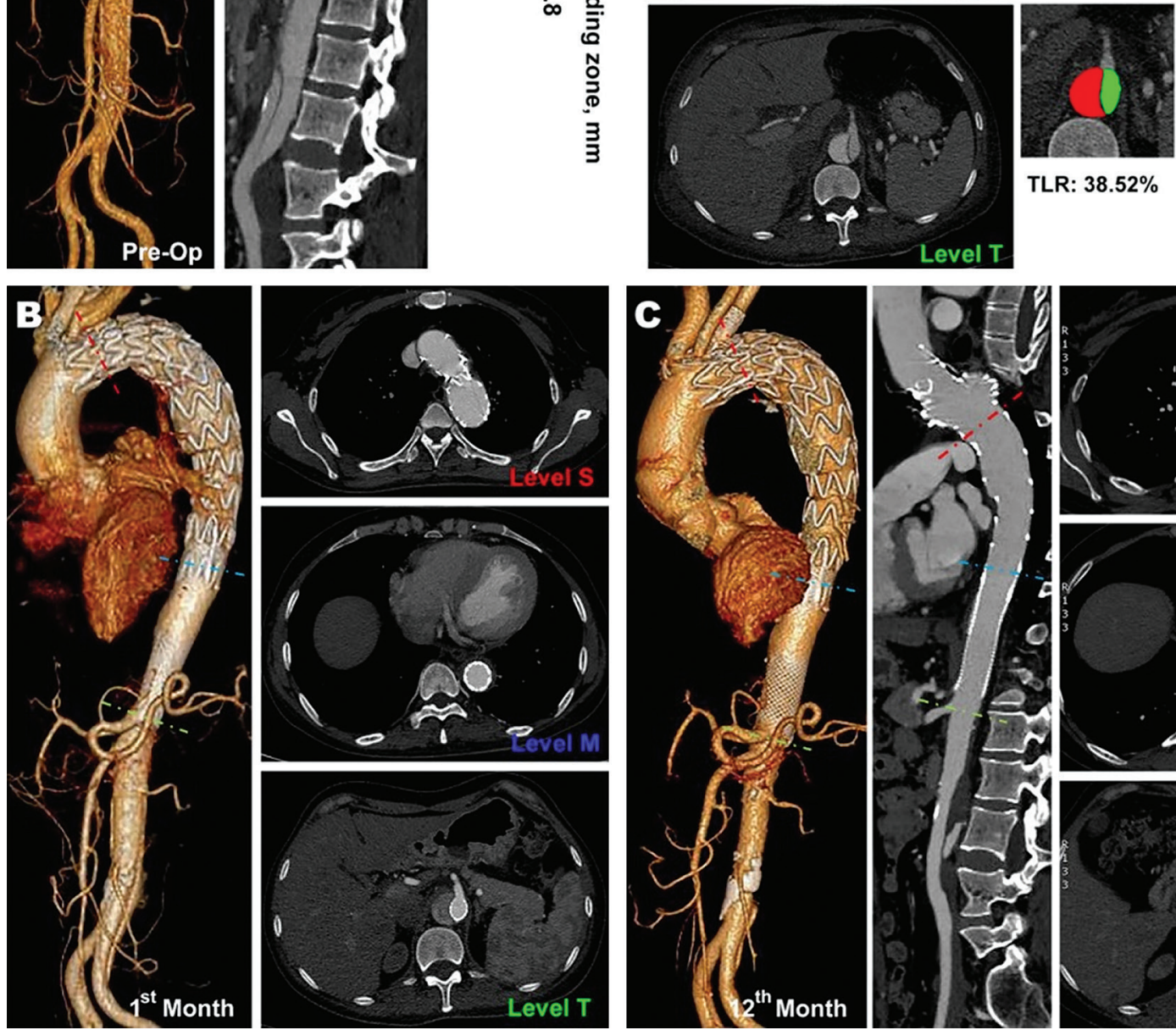

TLR: $\mathbf{3 8 . 5 2 \%}$
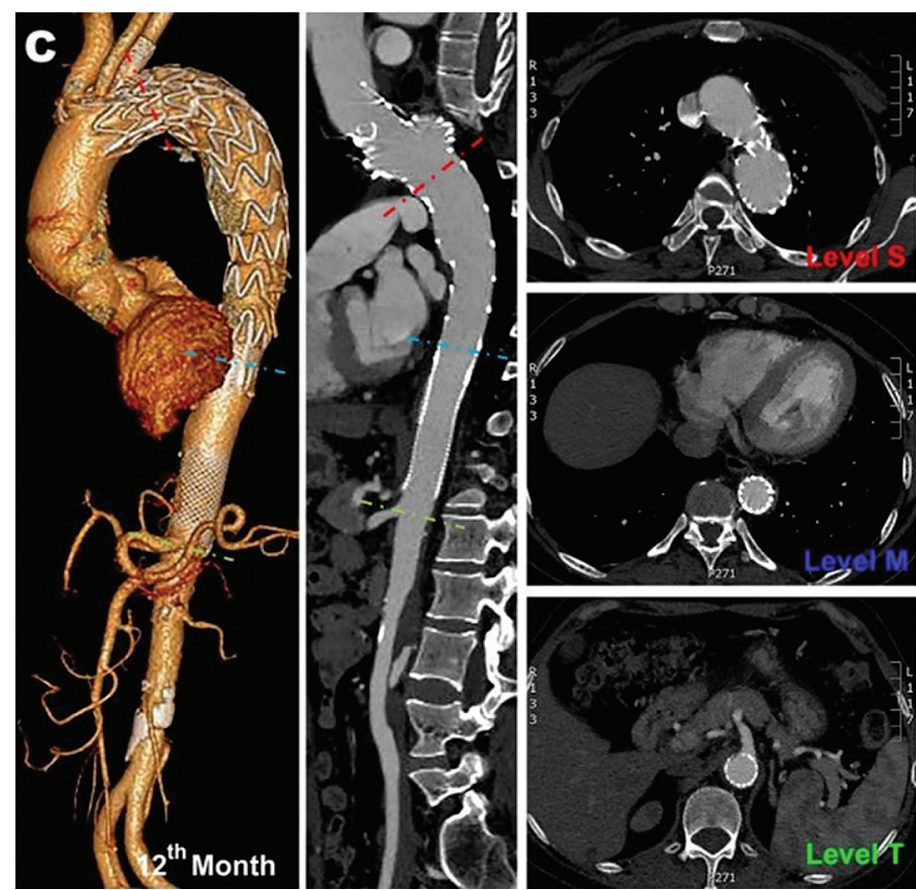

Fig. 2 TLR at LSA level (Level S), middle-thoracic aorta level (Level M) and coeliac trunk level (Level T). TLR: true lumen rate

neurological deficit. One patient (1.6\%) suffered myocardial infarction. Respiratory complications, including infection and respiratory failure, occurred in six patients $(9.5 \%)$. Access-site events included two hematomas and two puncture-site infections. No other complications occurred. The mean hospital stay was $10.1 \pm 5.2$ days (Table 2).

\section{Follow-up outcomes}

The mean follow-up time was $30.1 \pm 18.9$ months (median 30.2 months, range 1.3-70.6 months). During the follow-up period, the cumulative mortality was $3.1 \%$ $(\mathrm{n}=2)$. TEVAR-related mortality was $1.6 \%(\mathrm{n}=1)$ whom died because of multiple organ failure after RTAD during the sixth follow-up month, and the other death 
Table 1 Baseline characteristics and operation-related information $(\mathrm{N}=63)$

\begin{tabular}{|c|c|}
\hline Characteristics & $\mathrm{N}=63(\%)$ \\
\hline \multicolumn{2}{|l|}{ Demographic data } \\
\hline Male sex & $52(82.5)$ \\
\hline Age (years) & $54.2 \pm 12.4$ \\
\hline \multicolumn{2}{|l|}{ Risk factors } \\
\hline Smoking & $42(66.7)$ \\
\hline Hypertension & $51(81.0)$ \\
\hline Diabetes & $7(11.1)$ \\
\hline Hyperlipidemia & $15(23.8)$ \\
\hline \multicolumn{2}{|l|}{ Comorbidities } \\
\hline Coronary artery disease & $6(9.5)$ \\
\hline Peripheral artery disease & $9(14.3)$ \\
\hline Chronic renal failure & $16(25.3)$ \\
\hline Pulmonary disease & $9(14.3)$ \\
\hline \multicolumn{2}{|l|}{ Complications } \\
\hline Impending rupture & $2(3.2)$ \\
\hline Acute renal failure & $12(19.0)$ \\
\hline Visceral ischemia & $15(23.8)$ \\
\hline Refractory hypertension & $7(11.1)$ \\
\hline Refractory pain & $27(42.9)$ \\
\hline Technical success & $63(100)$ \\
\hline \multicolumn{2}{|l|}{ Anesthesia (n) } \\
\hline General & $33(52.7)$ \\
\hline Local & $30(47.6)$ \\
\hline Duration of procedure (min) & $57.3 \pm 24.2$ \\
\hline Intraoperative blood loss (ml) & $55.4 \pm 42.6$ \\
\hline Transfusion & $16(25.4)$ \\
\hline \multicolumn{2}{|l|}{ No. of stent graft (n) } \\
\hline 1 & $53(84.1)$ \\
\hline 2 & $10(15.9)$ \\
\hline Reconstruction of LSA (n) & $20(31.7)$ \\
\hline
\end{tabular}

Categorical variables are presented as number (\%). Continuous variables are presented as mean \pm standard deviation. RBS: restrictive bare stent

was caused by acute myocardial infarction (AMI) during the third follow-up month. Follow-up CTA showed that each ac-TBAD was well repaired without severe complications (e.g., retrograde stent displacement or fracture, stent-induced aneurysm). A distal endoleak was detected in one patient at the third month. Reintervention was performed to repair the leak (Table 2).

\section{TLR of aortic dissection: baseline data for all TBAD cases}

The TLRs were $34.7 \pm 4.6 \mathrm{~mm}$ and $32.9 \pm 32.3 \mathrm{~mm}$ of the mean diameter of the proximal landing zone and the distance from the break site to the LSA. The mean TLRs at levels S, M, and C were $67.9 \% \pm 24.4 \%, 54.8 \% \pm$ $22.1 \%$, and $67.4 \% \pm 26.7 \%$, respectively (Table 3). At level S, the TLRs were $86.3 \% \pm 16.2 \%$ (at 1 month), $95.7 \% \pm 5.0 \%$ (at 6 months), and $98.0 \% \pm 2.6 \%$ (at
Table 2 Thirty-day and follow-up outcomes

\begin{tabular}{|c|c|}
\hline Variables & $\mathrm{N}=63(\%)$ \\
\hline \multicolumn{2}{|l|}{ Thirty-day outcomes } \\
\hline Length of stay (days) & $10.1 \pm 5.2$ \\
\hline \multicolumn{2}{|l|}{ Perioperative complications (n) } \\
\hline Access site events & $6(9.5)$ \\
\hline Fever & $13(20.6)$ \\
\hline Type I/III endoleak & 0 \\
\hline Type II endoleak & $2(3.1)$ \\
\hline Cerebral events & 0 \\
\hline Spinal cord drainage & $2(3.1)$ \\
\hline Retrograde type A dissection & 0 \\
\hline Cardiac events & $1(1.6)$ \\
\hline Respiratory complications & $6(9.5)$ \\
\hline Access site complications & $6(9.5)$ \\
\hline In-hospital mortality (n) & 0 \\
\hline \multicolumn{2}{|l|}{ Follow-up outcomes } \\
\hline Mean follow-up time (months) & $30.1 \pm 18.9$ \\
\hline Median follow-up period (months) & $\begin{array}{c}30.2 \text { (range, } \\
1.3-70.6 \text { ) }\end{array}$ \\
\hline All-cause mortality during follow-up & $2(3.1)$ \\
\hline Aorta-related mortality & $1(1.6)$ \\
\hline Myocardial infarction & $1(1.6)$ \\
\hline \multicolumn{2}{|l|}{ Complications during follow-up } \\
\hline Stent displacement / fracture & 0 \\
\hline Type I/III endoleak & $1(1.6)$ \\
\hline Stent-induced new entry & 0 \\
\hline Retrograde type A dissection & $1(1.6)$ \\
\hline Secondary intervention & $1(1.6)$ \\
\hline
\end{tabular}

12 month). At level M, the TLR was $84.7 \% \pm 12.4 \%$ (at 1 month), $92.8 \% \pm 6.9 \%$ (at 6 months), and $96.9 \% \pm$ $3.1 \%$ (at 12 months). At level T, the TLRs were $91.7 \% \pm$ $7.2 \%$ (at 1 month), $96.8 \% \pm 3.1 \%$ (at 6 months), and $98.4 \% \pm 1.6 \%$ (at 12 months). These follow-up data show that the Ankura TAA Stent Graft can improve the TLR in patients with ac-TBAD.

\section{Discussion}

The main finding of this study was that the novel vascular-friendly Ankura Thoracic Stent Graft used for TEVAR was safe and effective. The technical success rate was $100 \%$, the all-cause mortality rate was $3.1 \%$, the cardiac events rate was $2.3 \%$, and the rate of reintervention was $1.6 \%$ (due to distal endoleaks). The two cases of spinal cord ischemia were immediately resolved by lumbar drainage, which left no permanent effect.

Compared with the results of covered stents in a previous study, ${ }^{16)}$ the Ankura Thoracic Stent Graft has a favorable incidence of complications. Minor type II endoleaks were found in two patients. They were left 
Table 3 True lumen rate of aortic

\begin{tabular}{lcccc}
\hline & \multicolumn{4}{c}{ Follow-up N=63(\%) } \\
\cline { 2 - 5 } & Baseline & 1 month & 6 months & 12 months \\
\hline LSA Level & $67.9 \% \pm 24.4 \%$ & $86.3 \% \pm 16.2 \%$ & $95.7 \% \pm 5.0 \%$ & $98.0 \% \pm 2.6 \%$ \\
Middle-thoracic aorta level & $54.8 \% \pm 22.1 \%$ & $84.7 \% \pm 12.4 \%$ & $92.8 \% \pm 6.9 \%$ & $96.9 \% \pm 3.1 \%$ \\
Coeliac trunk level & $67.4 \% \pm 26.7 \%$ & $91.7 \% \pm 7.2 \%$ & $96.8 \% \pm 3.1 \%$ & $98.4 \% \pm 1.6 \%$ \\
\hline
\end{tabular}

LSA: Left subclavian artery

untreated and disappeared during the follow-up period. Most complications were minor and easily managed. In our center, the Ankura Thoracic Stent Graft has been used for as-TBAD since 2013.

TEVAR plays an important role in advancing endovascular surgery, especially in treating acute aortic syndromes, such as acute penetrating ulcers and ac-TBADs. One study ${ }^{19)}$ showed that in-hospital mortality was significantly higher after open surgery $(33.9 \%)$ than after endovascular treatment $(10.6 \%, \mathrm{p}=0.002)$. Stelzmueller et al. $^{16)}$ reported that the mortality rate for TEVAR reached $9 \%$ because of the still-imperfect design of the existing stent graft for ac-TBAD. An ideal stent graft for treating ac-TBAD should meet the following two requirements: It minimizes irritation of blood vessels and maximizes compatibility with vascular morphology. In our study, all 63 patients had ac-TBAD, and the allcause mortality rate was $3.1 \%(n=2)$. TEVAR-related mortality was $1.6 \%(n=1)$. That patient died because of multiple organ failure 6 months after suffering RTAD.

The outcomes of Medtronic's Valiant Thoracic StentGraft System for acute aortic dissection have been reported. The Medtronic DISSECTION Trial ${ }^{20)}$ enrolled 50 patients at 16 institutions in the United States. At 12 months postoperatively, the true lumen diameter in the stented region remained stable or increased in 27 of the $29(93.1 \%)$ patients. False lumen diameters remained stable or decreased in 22 patients and were partially or completely thrombosed in $91 \%$. Our research showed that 57 of 63 patients $(90.40 \%)$ showed an improved TLR at 12 months. It appears that there is no significant difference between these two outcomes.

In the Bolton Relay RESTORE Patient Registry trial, ${ }^{21)} 30$ patients with acute aortic dissection underwent TEVAR with Relay stent grafts. The procedure was technically successful in $97 \%$ of these patients. Their type I endoleak rate was $7 \%$. Stent-related complications occurred in eight (9\%) patients, including six cases of stent-graft migrations, one failure to advance the delivery system, and one case of partial collapse of the stent graft. The rates of postoperative paraplegia, paraparesis, and stroke were $2 \%, 1 \%$, and $2 \%$, respectively. The 30 -day mortality was $13 \%$. The 1-year survival rate was $85 \%$ in the overall population and $98 \%$ when considering only stent-related death. Apparently, relevant data in our study precede the data presented above.

As far as we know, there is no study on this novel Vascular-Friendly Thoracic Stent Graft for the treatment of ac-TBAD. However, this study has several limitations that must be considered. It is a retrospective study without a control group. The study group comprises TEVAR patients treated with some other commercially available endografts or patients who underwent open repairs. This lack might have introduced selection bias. Moreover, the sample size and follow-up period are limited. Hence, further multi-center, prospective studies to assess its long-term performance are needed.

\section{Conclusion}

The novel vascular-friendly Ankura Thoracic Stent Graft showed satisfactory results, with favorable stability of the aortic diameter during follow-up.

\section{Ethics Approval}

Ethical Statement: The authors are accountable for all aspects of the work in ensuring that questions related to the accuracy or integrity of any part of the work are appropriately investigated and resolved. The study was conducted in accordance with the Declaration of Helsinki (as revised in 2013). The study was approved by institutional review board of Shanghai Changzheng Hospital and individual consent for this retrospective analysis was waived.

\section{Authors' Contributions}

(I) Conception and design: Lefeng Qu and Jie Jin

(II) Administrative support: Lefeng Qu

(III) Provision of study materials or patients: Qingjun Jiang and Bai Jun 
(IV) Collection and assembly of data: Jie Jin and Qingjun Jiang

(V) Data analysis and interpretation: Qingjun Jiang and Bai Jun

(VI) Manuscript writing: All authors

(VII) Final approval of manuscript: All authors

\section{Funding}

This work was supported by the National Natural Science Foundation of China (grant number 81870347); Clinical Science and Technology Innovation Technology Foundation of Shanghai (grant number SHDC12019117); Program of Shanghai Academic/Technology Research Leader (grant number 20XD1404900); and Special Professor Fund of University in Shanghai (grant number GZ2016008).

\section{Disclosure Statement}

No conflict of interest.

\section{References}

1) Trimarchi S, Nienaber CA, Rampoldi V, et al. Role and results of surgery in acute type B aortic dissection: insights from the International Registry of Acute Aortic Dissection (IRAD). Circulation 2006; 114: I357-64.

2) Hughes GC, Andersen ND, McCann RL. Management of acute type B aortic dissection. J Thorac Cardiovasc Surg 2013; 145: S202-7.

3) Svensson LG, Kouchoukos NT, Miller DC, et al. Expert consensus document on the treatment of descending thoracic aortic disease using endovascular stent-grafts. Ann Thorac Surg 2008; 85: S1-41.

4) Coady MA, Ikonomidis JS, Cheung AT, et al. Surgical management of descending thoracic aortic disease: open and endovascular approaches: a scientific statement from the American Heart Association. Circulation 2010; 121: 2780-804.

5) Khayat M, Cooper KJ, Khaja MS, et al. Endovascular management of acute aortic dissection. Cardiovasc Diagn Ther 2018; 8: S97-S107.

6) Kawamura S, Nishimaki H, Lin ZB, et al. Emergent endovascular stent-graft placement to treat ruptured Stanford type B acute aortic dissection. J Vasc Surg 2004; 39: 668-71.

7) Dake MD, Kato N, Mitchell RS, et al. Endovascular stent-graft placement for the treatment of acute aortic dissection. N Engl J Med 1999; 340: 1546-52.

8) An Z, Song Z, Tang H, et al. Retrograde type A dissection after thoracic endovascular aortic repair: surgical strategy and literature review. Heart Lung Circ 2018; 27: 629-34.

9) Yammine H, Briggs CS, Stanley GA, et al. Retrograde type A dissection after thoracic endovascular aortic repair for type B aortic dissection. J Vasc Surg 2019; 69: 24-33.

10) Geisbüsch P, Skrypnik D, Ante M, et al. Endograft migration after thoracic endovascular aortic repair. J Vasc Surg 2019; 69: 1387-94.

11) Liu Z, Zhang Y, Liu C, et al. Treatment of serious complications following endovascular aortic repair for type B thoracic aortic dissection. J Int Med Res 2017; 45: $1574-84$.

12) Boufi M, Aouini F, Guivier-Curien C, et al. Examination of factors in type I endoleak development after thoracic endovascular repair. J Vasc Surg 2015; 61: 317-23.

13) Li Q, Ma WG, Zheng J, et al. Distal stent graft-induced new entry after TEVAR of type B aortic dissection: experience in 15 years. Ann Thorac Surg 2019; 107: 718-24.

14) Sternbergh WC, Money SR, Greenberg RK, et al. Influence of endograft oversizing on device migration, endoleak, aneurysm shrinkage, and aortic neck dilation: results from the Zenith Multicenter Trial. J Vasc Surg 2004; 39: 20-6.

15) Tadros RO, Tang GHL, Barnes HJ, et al. Optimal treatment of uncomplicated type B aortic dissection: JACC review topic of the week. J Am Coll Cardiol 2019; 74: 1494-504.

16) Stelzmueller ME, Nolz R, Mahr S, et al. Thoracic endovascular repair for acute complicated type B aortic dissections. J Vasc Surg 2019; 69: 318-26.

17) Piffaretti G, Ottavi P, Lomazzi C, et al. Thoracic endovascular aortic repair for type B acute aortic dissection complicated by descending thoracic aneurysm. Eur $\mathbf{J}$ Vasc Endovasc Surg 2017; 53: 793-801.

18) Kratimenos $\mathrm{T}$, Antonopoulos $\mathrm{CN}$, Tomais $\mathrm{D}$, et al. Repair of descending thoracic aortic aneurysms with ankura thoracic stent graft. J Vasc Surg 2019; 69: 9961002.e3.

19) Fattori R, Tsai TT, Myrmel T, et al. Complicated acute type B dissection: is surgery still the best option?: a report from the International Registry of Acute Aortic Dissection. JACC Cardiovasc Interv 2008; 1: 395402.

20) Bavaria JE, Brinkman WT, Hughes GC, et al. Outcomes of thoracic endovascular aortic repair in acute type B aortic dissection: results from the valiant United States Investigational Device Exemption Study. Ann Thorac Surg 2015; 100: 802-08, 808-09.

21) Zipfel B, Czerny M, Funovics M, et al. Endovascular treatment of patients with types A and B thoracic aortic dissection using relay thoracic stent-grafts: results from the RESTORE Patient Registry. J Endovasc Ther 2011; 18: 131-43. 